\title{
Adverse events in thyroid surgery: observational study in three surgical units with high volume/year
}

\author{
Paolo Del Rio ${ }^{1}$, Paolo Carcoforo ${ }^{2}$, Fabio Medas ${ }^{3}$, Elena Bonati ${ }^{1 *}$, Tommaso Loderer ${ }^{1}$, \\ Margherita Koleva Radica ${ }^{2}$ and Piergiorgio Calò ${ }^{3}$
}

\begin{abstract}
Background: Thyroid surgery, performed for benign or malignant pathologies, is one of the most frequently performed procedures and its frequency has even been increasing in recent years. Postoperative bleeding, recurrent laryngeal nerve (RLN) palsy, associated to dysphonia, dysphagia, dyspnea, and hypoparathyroidism represent the most fearful and common complications. We conducted a multicenter, observational study of retrospectively collected data in three high-volume referral centers, enrolling all patients undergone to thyroid surgery between January 2016 and December 2017 in Parma University Hospital, Cagliari University Hospital and Ferrara University Hospital.
\end{abstract}

Materials: Patients were divided into five groups, differentiated thyroid carcinoma, medullary thyroid carcinoma, non-toxic benign pathology, hyperfunctioning benign pathology and NIFTP (Non-invasive Follicular Thyroid neoplasm with Papillary-like nuclear features). A follow up at 7 and 30 days was executed, evaluating the onset of paresthesia, dysphonia and dysphagia. A 6-month follow-up was conducted in cases of early complications.

Results: Totally, 1252 patients were eligible for the study: 907 female and 345 male, with a female to male ratio of 2.6:1 and an average age of 53.428. Total thyroidectomy was performed in 1022 cases, lobectomy in 230. After 6 months we recorded paresthesia in $0.5 \%$, dysphonia in $1.8 \%$ and dysphagia in $0.5 \%$.

Conclusion: Our study confirms once again that a share of morbidity escapes the possibilities of prediction and control by the operator, depending on patient anamnestic, pathological or anatomical factors.

Keywords: Vocal cord palsy, Thyroidectomy, Hypocalcemia, Postoperative bleeding, Dysphonia

\section{Introduction}

Thyroid surgery, performed for benign or malignant pathologies, is one of the most frequently performed procedures and its frequency has even been increasing in recent years with the increased incidence of differentiated thyroid cancer.

\footnotetext{
*Correspondence: elena.bonati@unipr.it

1 Unit of General Surgery, University Hospital of Parma, 14 Gramsci Road, Parma, Italy
}

Full list of author information is available at the end of the article
The incidence of post thyroidectomy complications has steadily decreased in recent decades, thanks to technical improvements and technological advances, reaching the lowest rates in high-volume referral centers [1-3].

Postoperative bleeding, recurrent laryngeal nerve (RLN) palsy, associated to dysphonia, dysphagia, dyspnea, and hypoparathyroidism represent the most fearful and common complications. Capsular dissection, visual identification and intraoperative nerve monitoring have reduced the incidence of RLN injury to $1-2 \%$ in tertiary referral centers, showing that in some cases neuronal 
damage must be consider an inevitable complication rather than a "surgical error" [4, 5].

Therefore, permanent complications can result in a marked deterioration in the patient's quality of life, affecting personal, social and working life. This is frequently cause of surgical malpractice claims.

For this reason, many studies have tried to identify predictive factors for the possible onset of complications, including characteristics of patient, of underlying disease or of surgical technique. In our study, we wanted to overcome the population variability deriving from different geographic areas and the variability in the surgical habits of different surgical teams, including patients undergoing surgery in three high-volume referral centers.

\section{Methods}

We conducted a multicenter, observational study of retrospectively collected data in three high-volume referral centers, enrolling all patients undergone to thyroid surgery between January 2016 and December 2017 in Parma University Hospital, Cagliari University Hospital and Ferrara University Hospital.

Totally, 1252 patients were eligible for the study. Collected data included patient demographics, anamnesis and clinical-instrumental-laboratory data, such as thyroid ultrasound pattern, preoperative diagnosis by ultrasound-guided fine needle aspiration (FNA) reported according to the Bethesda System for Reporting Thyroid Cytopathology [6], preoperative TSH, PTH and calcemic, X-ray trachea / CT neck, preoperative fibroscopy.

Intraoperative data included type of surgery performed (total thyroidectomy or lobectomy), number of parathyroid glands seen during surgery, lymph node dissection, use of intermittent intraoperative neuromonitoring (i-IONM), hemostatic agents, intraoperative administration of corticosteroids.

During hospitalization, bleeding, paresthesia, dysphonia, dysphagia, dyspnea, first day calcium value, first day PTH value, hospital therapy with intravenous calcium, oral calcium or corticosteroids, length of hospitalization were recorded. Paresthesia, dysphonia, dysphagia and dyspnea are subjectively reported by the patient during the clinical visit in case, respectively, of bilateral tingling in the extremities or perioral, voice alterations, alterations in swallowing, in particular fluids and breathing difficulties.

After hospitalization, we assessed any therapy with calcium and vitamin D, post-operative fibroscopy, definitive histopathological diagnosis, tumor size, angiovascular invasion, infiltration of perithyroid tissues, metastatic lymph nodes, presence of parathyroid glands in the specimen, radiometabolic therapy and speech therapy.
Based on definitive histological diagnosis, patients were divided into 5 groups, differentiated thyroid carcinoma, medullary thyroid carcinoma, non-toxic benign pathology, hyperfunctioning benign pathology and NIFTP (Non-invasive Follicular Thyroid neoplasm with Papillary-like nuclear features).

A follow up at 7 and 30 days was executed, through an outpatient visit, evaluating the onset of paresthesia, dysphonia and dysphagia. A 6-month follow-up was conducted in cases of early complications.

Only adult patients were included in the study, and patients previously undergone to thyroid surgery or presenting vocal cords pathologies on preoperative fibroscopy were excluded, as potential confounders.

Univariate analysis was conducted to evaluate the influence of demographic, preoperative, intraoperative, and pathological factors on postoperative complications, as potential effect modifier. The studied factors included, depending on the complication under consideration, age, sex, high blood pressure, use of anticoagulant/antiaggregant, type of intervention, intraoperative administration of corticosteroids, use of suction drainages, use and findings of IONM, use of hemostatic agents, pathological diagnosis, postoperative calcemic and presence of parathyroid glands in the specimen. In case of missing data, patient was excluded from the analysis. Chi-squared test and Student's t-test were used for categorical data and for continuous variables, respectively. Variables $<0.100$ in the univariate analysis were considered significant and were then included in the multivariate analysis. Logistic regression analysis was used to identify independent risk factors of postoperative complications. Results were considered statistically significant if $\mathrm{p}$-value was $<0.05$. All analyses were carried out using IBM SPSS Statistics, version 19.

\section{Results}

Patients included in the study were 1252, 907 female and 345 male, with a female to male ratio of $2.6: 1$ and an average age of 53.428. Considering the site of the intervention, 474 procedure were executed at Parma University Hospital, 504 at Cagliari and 274 at Ferrara University Hospital. Patients with missing data were previously excluded from the study.

Medium preoperative TSH was $1.562 \mathrm{uU} / \mathrm{ml}$ and calcium was $9.425 \mathrm{mg} / \mathrm{dl}$. Demographic and preoperative laboratory tests are reported in Table 1.

Preoperative cytological examination by FNA was performed in 715 patients and the result was reported according to the Bethesda System for Reporting Thyroid Cytopathology [6]. Results are reported in Table 2. Patients without suspected nodularity at preoperative thyroid ultrasound examination, such as diffuse 
Table 1 Demographic and preoperative laboratory tests

\begin{tabular}{|c|c|c|c|c|c|c|c|c|c|}
\hline & \multirow[t]{2}{*}{ Mean } & \multirow[t]{2}{*}{ Std error } & \multicolumn{2}{|c|}{$\begin{array}{l}95 \% \text { Confidence interval for } \\
\text { mean }\end{array}$} & \multirow{2}{*}{$\begin{array}{l}5 \% \\
\text { Trimmed } \\
\text { mean }\end{array}$} & \multirow[t]{2}{*}{ Median } & \multirow[t]{2}{*}{ Std deviation } & \multirow[t]{2}{*}{ Minimum } & \multirow[t]{2}{*}{ Maximum } \\
\hline & & & Lower bound & Upper bound & & & & & \\
\hline Age & 53.428 & 0.4012 & 52.641 & 54.215 & 53.579 & 54.000 & 14.1954 & 18.00 & 89.00 \\
\hline Preoperative TSH & 1.562 & 0.0396 & 1.484 & 1.639 & 1.452 & 1.309 & 1.2442 & 0.0 & 7.0 \\
\hline Preoperative serum calcium & 9.425 & 0.0144 & 9.397 & 9.453 & 9.412 & 9.400 & 0.4517 & 8.0 & 12.1 \\
\hline
\end{tabular}

Table 2 Preoperative cytological examination by fine needle aspiration (FNA), reported according to Bethesda System

\begin{tabular}{llcc}
\hline & & Frequency & Percent \\
\hline FNA & Thyr 1 & 26 & 2.1 \\
& Thyr 2 & 195 & 15.6 \\
& Thyr 3 & 89 & 7.1 \\
& Thyr 4 & 205 & 16.4 \\
& Thyr 5 & 63 & 5.0 \\
& Thyr 6 & 137 & 10.9 \\
& Total & 715 & 57.1 \\
Non executed & & 537 & 42.9 \\
Total & & 1252 & 100.0 \\
\hline
\end{tabular}

non-toxic goiter and colloidocystic goiter or Graves Basedow's disease, did not undergo cytological examination.

Total thyroidectomy was performed in 1022 cases, lobectomy in 230; in 130 patients, a lymph node dissection was also performed.

I-IONM was used in 958 procedures, according to the habits of the different operating units. In fact, in two centers it was routinely used while in one it was used only in complex selected cases, such as neoplasms suspected for perithyroid infiltration, voluminous goiters, reoperations or laterocervical lymphadenomies. In 24 cases a loss of signal was recorded. Overall, $8.9 \%$ of patients underwent postoperative fibroscopy, which was routinely performed by a surgeon while it was prescribed by other operators only in case of persistent dysphonia 30 days after surgery. Speech therapy was necessary in $3.4 \%$ of cases.

Complications arising on day 1 , day 7 , day 30 and at 6 months were then evaluated. On day 1, bleeding was found in $3.2 \%$ of patients, paresthesia in $6.4 \%$, dysphonia in $4.8 \%$. Calcemic in the first postoperative day showed an average value of $8.47 \mathrm{mg} / \mathrm{dl}$, ranging from a minimum of $5 \mathrm{mg} / \mathrm{dl}$ to a maximum of $12 \mathrm{mg} / \mathrm{dl}$. On the 7 th day, paresthesia were found in $1.7 \%$ of cases, dysphonia in $4.4 \%$, dysphagia in $0.9 \%$. On day 30 , paresthesia were found in $1.3 \%$ of patients, dysphonia in $3.8 \%$ and dysphagia in $0.3 \%$. After 6 months we recorded paresthesia in $0.5 \%$, dysphonia in $1.8 \%$ and dysphagia in $0.5 \%$.
Table 3 Postoperative complication and type of intervention

\begin{tabular}{|c|c|c|c|c|}
\hline & & $\begin{array}{l}\text { Hemithyroidectomy } \\
\text { (\%) }\end{array}$ & $\begin{array}{l}\text { Total } \\
\text { thyroidectomy } \\
\text { (\%) }\end{array}$ & P value \\
\hline Bleeding & Day 1 & 1.9 & 3.7 & 0.214 \\
\hline \multirow[t]{4}{*}{ Parestesia } & Day 1 & 0.9 & 8.0 & 0.000 \\
\hline & Day 7 & 1.4 & 1.9 & 0.700 \\
\hline & Day 30 & 1.4 & 1.3 & 0.269 \\
\hline & $\begin{array}{l}6 \\
\text { Months }\end{array}$ & 0.5 & 0.6 & 0.900 \\
\hline \multirow{4}{*}{$\begin{array}{l}\text { Dyspho- } \\
\text { nia }\end{array}$} & Day 1 & 1.9 & 5.9 & 0.021 \\
\hline & Day 7 & 6.3 & 3.7 & 0.129 \\
\hline & Day 30 & 5.8 & 3.0 & 0.052 \\
\hline & 6 Month & 2.9 & 1.3 & 0.139 \\
\hline \multirow[t]{3}{*}{ Dysphnea } & Day 7 & 1.0 & 0.9 & 0.273 \\
\hline & Day 30 & 0.5 & 0.2 & 0.483 \\
\hline & 6 Month & 1.0 & 0.4 & 0.320 \\
\hline
\end{tabular}

The relationship between the type of surgery (lobectomy or total thyroidectomy) and the onset of complications at the various established follow-up steps (1st, 7 th, 30th day and 6 months) was analyzed. (Table 3).

Bleeding on day 1 occurred in $1.9 \%$ of patients undergoing lobectomy and in $3.7 \%$ of patients undergoing total thyroidectomy, with no statistically significant difference. Paresthesia occurred on day 1 in $0.9 \%$ of patients undergoing lobectomy, while in patients undergoing total thyroidectomy they occurred in $8 \%$, thus showing a statistically significant correlation $(\mathrm{p}=0.000)$. The correlation between dysphonia in day 1 and type of intervention also proved to be statistically significant, occurring in $5.9 \%$ of patients who underwent total thyroidectomy (5.9\%), while only in $1.9 \%$ of lobectomy cases. Regarding the complications arising on day 7, 30 and after 6 months (paresthesia, dysphonia, dysphagia) no significant correlations emerged; however, there is a higher percentage of dysphonia among lobectomies (6.3\%) compared to total thyroidectomies (3.7\%), in all follow-up phases. Nevertheless, among patients undergoing lobectomy who presented dysphonia on day 7 , a loss of NIM signal was 
recorded in $76.9 \%$, there was no loss of IONM signal in $7.7 \%$ and the IONM has not been used in $15.4 \%$

As this is a retrospective study, it was not possible to trace which of these patients were originally enrolled for a total thyroidectomy and therefore how many procedures became lobectomies due to intraoperative NIM signal loss, according to the indications of the two stage thyroidectomy [7]. In the pre-IONM era, these cases would have relapsed into the group of patients undergoing total thyroidectomy.

Considering the loss of NIM signal and the onset of dysphonia on the entire sample of patients, only one patient presented this association on the 1st postoperative day, while we found a statistically significant association on the 7th $(\mathrm{p}=0.000)$ and 30th day $(\mathrm{p}=0.000)$ and after 6 months $(\mathrm{p}<0.001)$.

It was then assessed whether the onset of paresthesia could correlate with the calcemic values detected on the 1 st postoperative day. Paresthesia were recorded in $6.48 \%$ of cases in the first postoperative day. Oral calcium supplementation during hospitalization was introduced only in case of onset of paraesthesia.

In patients without paresthesia on day 1 , the calcium has an average value of $8.53 \mathrm{mg} / \mathrm{dl}$, with a minimum of $7 \mathrm{mg} / \mathrm{dl}$ and a maximum $12 \mathrm{mg} / \mathrm{dl}$, while in patients who presented paresthesia the average calcium is attests to a significantly lower value of $7.59 \mathrm{mg} / \mathrm{dl}$ on average, with a minimum value of $5 \mathrm{mg} / \mathrm{dl}$ and a maximum of $9 \mathrm{mg} / \mathrm{dl}$. A correlation between the calcemic value in the first day and the development of paresthesia was highlighted in all the stages considered $(p=0.000$ in the 1st, 7 th and 30th day, $\mathrm{p}=0.004$ at 6 months).

A correlation was sought between the onset of paresthesia and the presence of parathyroid glands in the surgical specimen. However, no statistically significant relationships emerged. In fact, only $9.2 \%$ of patients with presence of parathyroid glands at the definitive histological examination, presented paresthesia on the first day, on the 7 th day $2.5 \%$ and on the 30 th day $1.7 \%$; on the other hand, among patients negative for the presence of parathyroid glands, paresthesia were recorded in $1.6 \%$ in day 7 and in $1.3 \%$ in 30th.

After 6 months, among patients in whom the presence of parathyroid glands was found, there was not even one case of paresthesia, while $0.6 \%$ of those who did not have parathyroid glands accidentally removed at the final histological examination were recorded.

The mean length of hospitalization was 2.459 days, showing a minimum of 1 day and a maximum of 14 days. Patients who experienced bleeding on day 1 had a hospital stay of 4.174 days while those who did not have bleeding reported a mean hospital stay of 2.076 days. Even the onset of paresthesia in the first day minimally prolonged hospitalization, with an average duration of 2.625 days compared to 2.265 days for patients without paresthesia. Similarly, the development of dysphonia in day 1 led to an average hospital stay of 3.730 days compared to 2.062 days for patients without dysphonia. Analyzing data with the Kruskall-Wallis test, a statistically significant difference was highlighted between the hospitalization of patients who presented at least one of the complications considered in the 1 first day and the duration of hospitalization ( $<<0.000$ in all cases).

Finally, we evaluated the possible association between thyroid disease, divided into 5 diagnostic categories (differentiated carcinoma, medullary carcinoma, non-hyperfunctioning benign disease, hyperfunctioning benign disease, NIFTP) and the onset of complications.

The analysis found only a statistically significant correlation between the hyperfunctioning benign disease and the onset of bleeding and paresthesia in first postoperative day. No association was recorded between thyroiditis on pathology specimen and postoperative complications. Full results are shown in Table 4.

At multivariate analysis, intraoperative corticosteroid administration (OR $=5.682$; CI: $1.2329-26.1859$; $\mathrm{p}=0.025)$ and the use of haemostatic agent during surgery $(\mathrm{OR}=2,928$; $\mathrm{CI}$ : $1.1383-7.5345 ; \mathrm{p}=0.025)$ were found as independent risk factors for postoperative dysphonia (Fig. 1).

Male sex $(\mathrm{OR}=4.606 ; \mathrm{CI}: 1.8132-11,7053 ; \mathrm{p}=0.001)$ was found as independent predictive factor for postoperative bleeding (Fig. 2); and a postoperative calce$\mathrm{mia}<8.0 \mathrm{mg} / \mathrm{dl}(\mathrm{OR}=7.994 ; \mathrm{CI}: 3.555-17.9763 ; \mathrm{p}<0.001)$ was identified as independent predictive factor for paraesthesia (Fig. 3).

\section{Discussion}

Thyroid surgery, although with a low incidence, can present some specific postoperative complications that have a strong impact on the patient's quality of life and are often a source of medico-legal dispute.

The incidence rates reported in the literature are highly variable and primarily influenced by the surgeon's experience and by the volume of the center. All studies agree that operations performed by experienced surgeons and in high volume centers ( $>100$ thyroidectomies / year) show a lower complication rate and a shorter hospital stay [8].

In particular, it has been shown that the length of stay and complications are more determined by the surgeon experience than by hospital volume, which does not have a consistent association with the results [3].

Some study described also a threshold ( $>25$ total thyroidectomies/y) that identify a high-volume thyroid 
Table 4 Postoperative complication and histological diagnosis

\begin{tabular}{|c|c|c|c|c|c|c|c|}
\hline & & CDT (\%) & CM (\%) & NT-BTD (\%) & T-BTD (\%) & NIFTP (\%) & $P$ value \\
\hline Bleeding & Day 1 & 3.4 & 0.0 & 2.0 & 15.8 & 0.0 & 0.014 \\
\hline \multirow[t]{4}{*}{ Parestesia } & Day 1 & 8.4 & 0.0 & 4.0 & 16.4 & 0.0 & 0.001 \\
\hline & Day 7 & 2.2 & 0.0 & 1.3 & 0.0 & 0.0 & 0.856 \\
\hline & Day 30 & 1.9 & 0.0 & 0.8 & 0.0 & 0.0 & 0.936 \\
\hline & 6 Months & 0.3 & 0.0 & 0.5 & 0.0 & 0.0 & 0.991 \\
\hline \multirow[t]{4}{*}{ Dysphonia } & Day 1 & 4.3 & 0.0 & 5.3 & 10.5 & 0.0 & 0.717 \\
\hline & Day 7 & 4.7 & 0.0 & 4.4 & 0.0 & 0.0 & 0.867 \\
\hline & Day 30 & 3.1 & 0.0 & 4.4 & 0.0 & 0.0 & 0.951 \\
\hline & 6 Month & 1.3 & 0.0 & 2.1 & 0.0 & 0.0 & 0.877 \\
\hline \multirow[t]{3}{*}{ Dysphnea } & Day 7 & 0.9 & 0.0 & 0.5 & 5.9 & 0.0 & 0.555 \\
\hline & Day 30 & 0.3 & 0.0 & 0.0 & 0.0 & 0.0 & 0.862 \\
\hline & 6 Month & 0.3 & 0.0 & 0.5 & 0.0 & 0.0 & 0.990 \\
\hline
\end{tabular}

CDT differentiated thyroid carcinoma, CM medullary carcinoma, NT-BTD non-toxic benign thyroid disease, T-BTD toxic benign thyroid disease, NIFTP non-invasive follicular thyroid neoplasm with papillary-like nuclear features

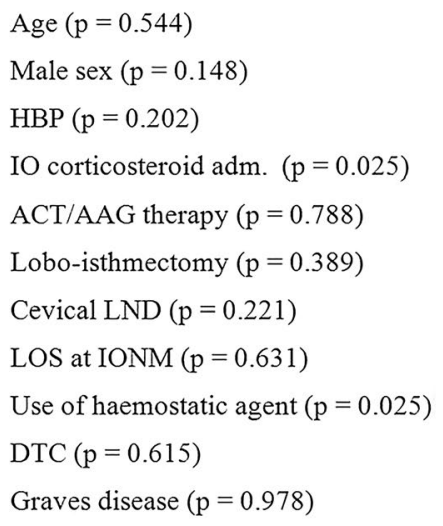

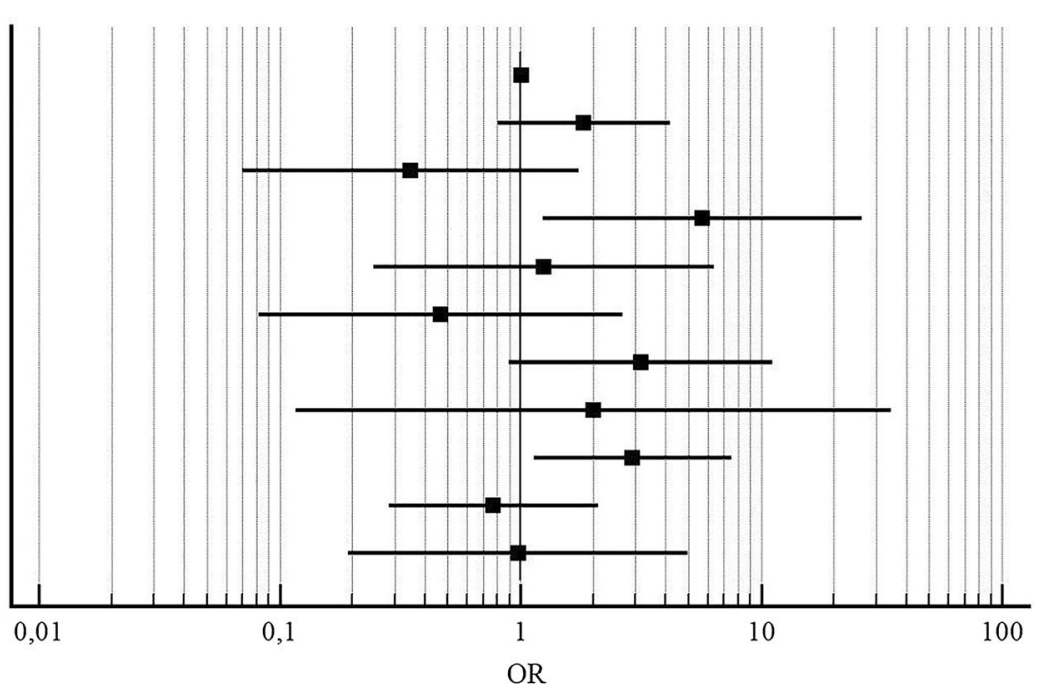

Fig. 1 Forest plot reporting results of multivariate analysis considering postoperative dysphonia as dependent variable. OR odds ratio, HBP high blood pressure, $1 O$ intraoperative, ACT/AAG anticoagulant/antiaggregant, LND lymph node dissection, LOS loss of signal, IONM intraoperative nerve monitoring, DTC differentiated thyroid carcinoma. X axis is reported in logarithmic scale surgeon and it is associated with improved patient outcomes [9].

In our multicenter study, Parma, Cagliari and Ferrara University Hospital are high-volume referral centers and high-volume thyroid surgeons have executed all procedures included. This led to the finding of a low complication rate, uniform among the three centers despite differences in surgical practice, first in the use of the IONM. In particular, the average incidence of definitive dysphonia settles at $1.8 \%$ in our series, with literature reported rate from 0.7 to $5.65 \%$ [10-13].
Direct visualization of the RLN still remains the cornerstone of avoiding damage, while the non-visualization during dissection causes the highest risk for nerve palsy occurrence. No consensus exist regarding the utility of IONM. In particular, different studies have compared neural visualization and dissection alone to identification plus intraoperative use of NIM, without the evidence of any statistically significant difference [14-17]. Anaway, the routinary use of NIM has the enormous advantage to avoid bilateral palsy in case of loss of signal on the initial site, forcing to stop the operation [18-20]. After RLN palsy, the recovery of the 


$$
\begin{aligned}
& \text { Age }(p=0.453) \\
& \text { Male sex }(p=0.001) \\
& \text { HBP }(p=0.610) \\
& \text { ACT/AAG therapy }(p=0.105) \\
& \text { IO corticosteroid adm. }(p=0.424) \\
& \text { Lobo-isthmectomy }(p=0.250) \\
& \text { Cervical LND }(p=0.221) \\
& \text { Graves disease }(p=0.493)
\end{aligned}
$$

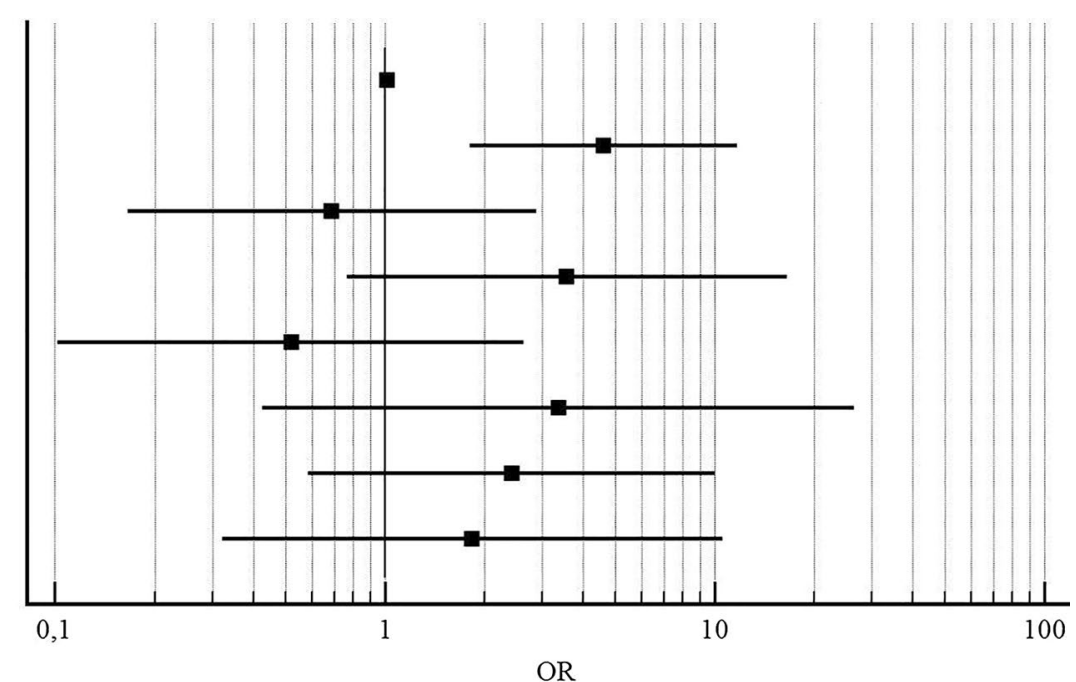

Fig. 2 Forest plot reporting results of multivariate analysis considering postoperative bleeding as dependent variable. OR odds ratio, $H B P$ high blood pressure, ACT/AAG anticoagulant/antiaggregant, IO intraoperative, LND lymph node dissection. $X$ axis is reported in logarithmic scale.

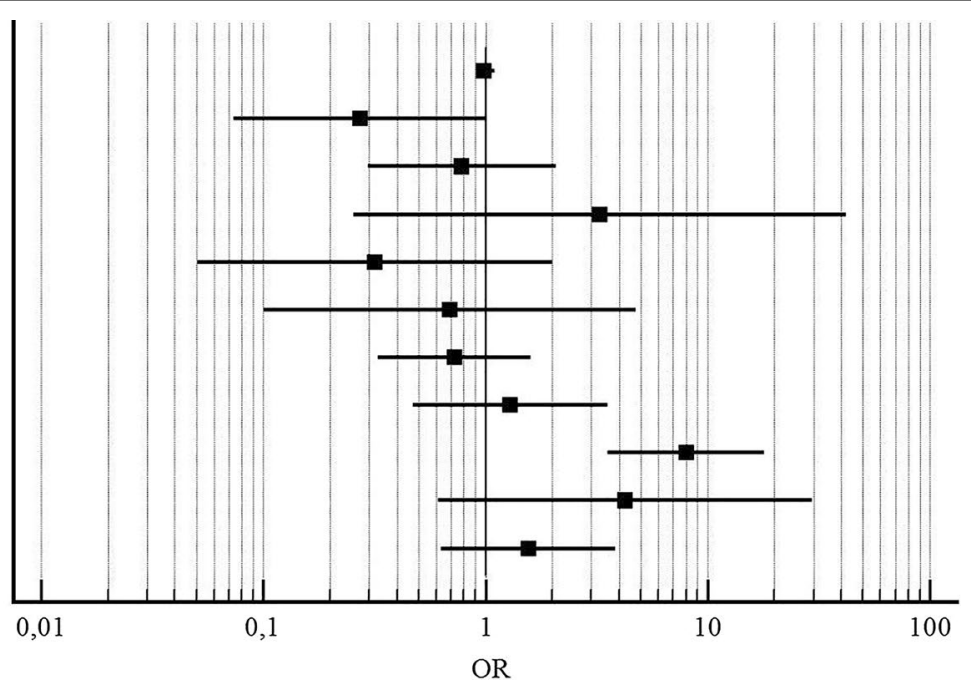

Fig. 3 Forest plot reporting results of multivariate analysis considering postoperative paraesthesia as dependent variable. $O R$ odds ratio, $H B P$ high blood pressure, ACT/AAG anticoagulant/antiaggregant, LND lymph node dissection, $P O D 1$ postoperative day $1, P G$ parathyroid glands. $X$ axis is reported in logarithmic scale. nerve at one year is expected to be as high as $95 \%$ when the anatomic integrity is confirmed during the procedure. Consequently, the non-visualization of the nerve during dissection represents a striking risk factor for permanent damage [10].

Additionally, it has been reported that a large thyroid mass predicts a poor recovery after RLN injury, but this do not represent an independent risk factor for complications [17].
In our study, the use of hemostatic agents during surgery was found as independent risk factors for postoperative dysphonia, probably due to a greater use of coagulation instruments too in a more bloody operating field during procedure, with greater risk of thermal nerve injury, or due to the development of postoperative adhesions, which alter normal pharyngo-laryngeal mobility.

The development of muscle adhesions, which impair mobility, can also causes an associated dysphagia. This 
complication has a more complex pathogenesis, related to trauma from orotracheal intubation, postoperative tissue swelling and presence of pre-existing functional gastroesophageal disorders. For the most part, however, these are transient disturbances, which recede spontaneously [21-23].

Minor surgical trauma and reduced postoperative pain could be responsible in part for the better vocal and swallowing outcomes found in patients operated with MIVAT technique $[24,25]$.

Thyroiditis on pathology specimen is not associated with increased postoperative complications in our study, while the presence of thyroid hyperfunction is associated with both an increased rate of bleeding and transient hypoparathyroidism with paresthesia, as confirmed in literature [26-29].

Paraesthesias is the most frequent postoperative complication, related to the lowering of serum calcium levels in the postoperative period. It can be attributed to a number of causes, which can also coexist, such as hemodilution associated with surgical stress, decreased renal tubular reabsorption, vitamin $\mathrm{D}$ deficiency and acute increase in calcitonin levels. The main cause of hypocalcemia after thyroidectomy appears to be hypoparathyroidism [30-32].

Lymph node dissection and female gender are associated with this complication, as previously suggested in case series, but parathyroid function recovery is not affected by these factors [33-36].

Considering the lack of association between the accidental removal of parathyroid glands and the onset of paresthesias, which however correlate with the levels of calcium in the first postoperative day, our study seems to suggest that postoperative hypocalcemia depends on numerous surgical and personal factors of the patient, difficult to predict.

\section{Conclusions}

The possible complications resulting from thyroid surgery have a strong impact on patients and are frequently the cause of medico-legal disputes. Despite the technological improvement, the volume of the dedicated thyroid surgeon and the meticulous dissection and visualization of the intraoperative RLN, remain the gold standards for decreasing the incidence of complications. In our study, compared to an equal volume of centers involved and equal experience of surgeons, the different technologies or protocols routinely applied did not influence the outcomes, as some centers routinely use the I-IONM while others occasionally and different devices are used during intervention, based on surgeons' habits. Overall, low complication rates were recorded, however not zero.
This confirms once again that a share of morbidity escapes the possibilities of prediction and control by the operator, depending on patient anamnestic, pathological or anatomical factors.

\section{Acknowledgements \\ Not applicable.}

\section{Authors' contributions}

Conception and design: RDP, PGC, PC. Administrative support: EB Provision of study materials or patients: EB, RMK, FM. Collection and assembly of data: TL, RMK, FM. Data analysis and interpretation: EB, FM. Manuscript writing: all authors. All authors read and approved the final manuscript.

\section{Funding}

None

\section{Availability of data and materials}

The datasets used and analysed during the current study are available from the corresponding author on reasonable request.

\section{Declarations}

\section{Ethics approval and consent to participate}

The authors are accountable for all aspects of the work in ensuring that questions related to the accuracy or integrity of any part of the work are appropriately investigated and resolved. The study was conducted in accordance with the Declaration of Helsinki (as revised in 2013). Institutional ethics board of Area Vasta Emilia Nord (AVEN) approved the study (NO.: 1155/2018/OSS/ AOUPR, protocol number 2881 on 21/01/2019). The authors have produced the manuscript according to STROBE reporting check-list. An informed consent to participate in the study has been approved by the same institutional ethic board and obtained from participants.

\section{Consent for publication}

Not applicable.

\section{Competing interests}

The authors have no competing interests to declare.

\section{Author details}

${ }^{1}$ Unit of General Surgery, University Hospital of Parma, 14 Gramsci Road, Parma, Italy. ${ }^{2}$ Unit of General Surgery, University Hospital of Ferrara, Cona, Italy. ${ }^{3}$ Unit of General Surgery, University Hospital of Cagliari, Cagliari, Italy.

Received: 21 November 2020 Accepted: 28 August 2021

Published online: 25 September 2021

\section{References}

1. Conzo G, Avenia N, Bellastella G, et al. The role of surgery in the current management of differentiated thyroid cancer. Endocrine. 2014:47:380-8.

2. Giddings AE. The history of thyroidectomy. J R Soc Med. 1998;91(Suppl 33):3-6.

3. Sosa JA, Bowman HM, Tielsch JM, Powe NR, Gordon TA, Udelsman R. The importance of surgeon experience for clinical and economic outcomes from thyroidectomy. Ann Surg. 1998;228:320-30.

4. Gambardella C, Polistena A, Sanguinetti A, et al. Unintentional recurrent laryngeal nerve injuries following thyroidectomy: is it the surgeon who pays the bill? Int J Surg. 2017;41(Suppl 1):S55-9.

5. Hayward NJ, Grodski S, Yeung M, Johnson WR, Serpell J. Recurrent laryngeal nerve injuryin thyroid surgery: a review. ANZ J Surg. 2013;83:15-21.

6. Cibas ES, Ali SZ. The Bethesda system for reporting thyroid cytopathology. Thyroid. 2009;19(11):1159-65.

7. Calò PG, Medas F, Conzo G, et al. Intraoperative neuromonitoring in thyroid surgery: is the two-staged thyroidectomy justified? Int J Surg 2017:41(Suppl 1):S13-20. 
8. Liang TJ, Liu SI, Mok KT, Shi HY. Associations of volume and thyroidectomy outcomes: a nationwide study with systematic review and meta-analysis. Otolaryngol Head Neck Surg. 2016;155(1):65-75. https://doi.org/10.1177/ 0194599816634627 (Epub 2016 Mar 1).

9. Adam MA, Thomas $S$, Youngwirth $L$, et al. Is there a minimum number of thyroidectomies a surgeon should perform to optimize patient outcomes? Ann Surg. 2017;265(2):402-7.

10. Daher R, Lifante JC, Voirin N. et al; CATHY Study Group. Is it possible to limit the risks of thyroid surgery? Ann Endocrinol (Paris). 2015;76(Suppl 1):1S16-26.

11. Chiang FY, Wang LF, Huang YF, Lee KW, Kuo WR. Recurrent laryngeal nerve palsy after thyroidectomy with routine identification of the recurrent laryngeal nerve. Surgery. 2005;137(3):342-7.

12. Rosato L, Avenia N, Bernante P, et al. Complications of thyroid surgery: analysis of a multicentric study on 14,934 patients operated on in Italy over 5 years. World J Surg. 2004;28(3):271-6.

13. Thomusch $O$, Machens $A$, Sekulla C, et al. Multivariate analysis of risk fac tors for postoperative complications in benign goiter surgery: prospective multicenter study in Germany. World J Surg. 2000;24(11):1335-41.

14. Shindo ML, Wu JC, Park EE. Surgical anatomy of the recurrent laryngeal nerve revisited. Otolaryngol Head Neck Surg. 2005;133(4):514-9.

15. Abadin SS, Kaplan EL, Angelos P. Malpractice litigation after thyroid surgery: the role of recurrent laryngeal nerve injuries, 1989-2009. Surgery. 2010;148(4):718-22; discussion 722-3. https://doi.org/10.1016/j.surg.2010. 07.019 (Epub 2010 Aug 14).

16. Pisanu A, Porceddu G, Podda M, Cois A, Uccheddu A. Systematic review with meta-analysis of studies comparing intraoperative neuromonitoring of recurrent laryngeal nerves versus visualization alone during thyroidectomy. J Surg Res. 2014;188(1):152-61. https://doi.org/10.1016/j.jss.2013. 12.022 (Epub 2013 Dec 25).

17. Calò PG, Pisano G, Medas F, et al. Identification alone versus intraoperative neuromonitoring of the recurrent laryngeal nerve during thyroid surgery: experience of 2034 consecutive patients. J Otolaryngol Head Neck Surg. 2014;43(1):16

18. Wu CW, Sun H, Zhang G, Kim HY, Catalfamo A, Portinari M, Carcoforo P, Randolph GW, Chai YJ, Dionigi G. Staged thyroidectomy: a single institution perspective. Laryngosc Investig Otolaryngol. 2018;3(4):326-32.

19. Calò PG, Medas F, Gordini L, et al. Interpretation of intraoperative recurrent laryngeal nerve monitoring signals: the importance of a correct standardization. Int J Surg. 2016;28(Suppl 1):S54-8.

20. Del Rio P, Cozzani F, Puteo N, Loderer T, Rossini M, Bonati E. IONM and thyroidectomy in benign thyroid disease. Analysis of adverse events. $G$ Chir. 2019;40(3):174-81.

21. Galluzzi F, Garavello W. Dysphagia following uncomplicated thyroidectomy: a systematic review. Eur Arch Otorhinolaryngol. 2019;276(10):266171. https://doi.org/10.1007/s00405-019-05599-y (Epub 2019 Aug 14).

22. Scerrino G, Tudisca C, Bonventre S, et al. Swallowing disorders after thyroidectomy: what we know and where we are. A systematic review. Int J Surg. 2017;41(Suppl 1):S94-102.
23. Lombardi CP, D'Alatri L, Marchese MR, et al. Prospective electromyographic evaluation of functional postthyroidectomy voice and swallowing symptoms. World J Surg. 2012;36(6):1354-60.

24. Del Rio P, Cozzani F, Nisi PC, Loderer T, Piva G, Bonati E. IONM and minimally invasive videoassisted thyroidectomy. G Chir. 2018;34(5):291-6.

25. Miccoli P, Fregoli L, Rossi L, et al. Minimally invasive video-assisted thyroidectomy (MIVAT). Gland Surg. 2020;9(Suppl 1):S1-5.

26. Liu J, Sun W, Dong W, et al. Risk factors for post-thyroidectomy haemorrhage: a meta-analysis. Eur J Endocrinol. 2017;176(5):591-602.

27. Edafe O, Antakia R, Laskar N, Uttley L, Balasubramanian SP. Systematic review and meta-analysis of predictors of post-thyroidectomy hypocalcaemia. Br J Surg. 2014;101(4):307-20.

28. Hallgrimsson P, Nordenström E, Bergenfelz A, Almquist M. Hypocalcaemia after total thyroidectomy for Graves' disease and for benign atoxic multinodular goitre. Langenbecks Arch Surg. 2012;397(7):1133-7.

29. Welch KC, McHenry CR. Total thyroidectomy: is morbidity higher for Graves' disease than nontoxic goiter? J Surg Res. 2011;170(1):96-9.

30. Carvalho GB, Giraldo LR, Lira RB, et al. Preoperative vitamin D deficiency is a risk factor for postoperative hypocalcemia in patients undergoing total thyroidectomy: retrospective cohort study. Sao Paulo Med J. 2019;137(3):241-7.

31. Eismontas $\vee$, Slepavicius $A$, Janusonis $V$, et al. Predictors of postoperative hypocalcemia occurring after a total thyroidectomy: results of prospective multicenter study. BMC Surg. 2018;18(1):55.

32. Vibhatavata P, Pisarnturakit $P$, Boonsripitayanon M, Pithuksurachai $P$, Plengvidhya N, Sirinvaravong S. Effect of preoperative vitamin D deficiency on hypocalcemia in patients with acute hypoparathyroidism after thyroidectomy. Int J Endocrinol. 2020;22(2020):5162496.

33. Sitges-Serra A, Ruiz S, Girvent M, Manjón H, Dueñas JP, Sancho JJ. Outcome of protracted hypoparathyroidism after total thyroidectomy. Br J Surg. 2010;97(11):1687-95.

34. Paek SH, Lee YM, Min SY, Kim SW, Chung KW, Youn YK. Risk factors of hypoparathyroidism following total thyroidectomy for thyroid cancer. World J Surg. 2013;37(1):94-101.

35. Carcoforo P, Portinari M, Feggi L, et al. Radio-guided selective compartment neck dissection improves staging in papillary thyroid carcinoma: a prospective study on 345 patients with a 3-year follow up. Surgery. 2014;156(1):147-57.

36. Del Rio P, Rossini M, Montana CM, et al. Postoperative hypocalcemia: analysis of factors influencing early hypocalcemia development following thyroid surgery. BMC Surg. 2019;18(Suppl 1):25.

\section{Publisher's Note}

Springer Nature remains neutral with regard to jurisdictional claims in published maps and institutional affiliations.

\footnotetext{
Ready to submit your research? Choose BMC and benefit from:

- fast, convenient online submission

- thorough peer review by experienced researchers in your field

- rapid publication on acceptance

- support for research data, including large and complex data types

- gold Open Access which fosters wider collaboration and increased citations

- maximum visibility for your research: over $100 \mathrm{M}$ website views per year
}

At BMC, research is always in progress.

Learn more biomedcentral.com/submissions 